Review

\title{
Active Packaging Coatings
}

\section{Luis J. Bastarrachea, Dana E. Wong, Maxine J. Roman, Zhuangsheng Lin and Julie M. Goddard *}

Department of Food Science, University of Massachusetts Amherst, 102 Holdsworth Way, Amherst, MA 01003, USA; E-Mails: lbastarr@foodsci.umass.edu (L.J.B.); dewong@foodsci.umass.edu (D.E.W.); mjroman@foodsci.umass.edu (M.J.R.); zhuangshengl@foodsci.umass.edu (Z.L.)

* Author to whom correspondence should be addressed; E-Mail: goddard@foodsci.umass.edu; Tel.: +1-413-545-2275; Fax: +1-413-545-1262.

Academic Editor: Stefano Farris

Received: 25 September 2015 / Accepted: 30 October 2015 / Published: 6 November 2015

\begin{abstract}
Active food packaging involves the packaging of foods with materials that provide an enhanced functionality, such as antimicrobial, antioxidant or biocatalytic functions. This can be achieved through the incorporation of active compounds into the matrix of the commonly used packaging materials, or by the application of coatings with the corresponding functionality through surface modification. The latter option offers the advantage of preserving the packaging materials' bulk properties nearly intact. Herein, different coating technologies like embedding for controlled release, immobilization, layer-by-layer deposition, and photografting are explained and their potential application for active food packaging is explored and discussed.
\end{abstract}

Keywords: active food packaging; antimicrobial; antioxidant; biocatalytic; surface modification

\section{Introduction}

Active packaging, in which the packaging material performs an additional function beyond containment and basic protection, remains an area of active research with great potential for commercial applications. Active packaging has application in packaging of food, pharmaceutical, and consumer goods products, with a common goal of improving shelf life, safety, or quality of packaged goods. A number of excellent reviews have been written on targeted applications of active packaging materials with less focus on 
material synthesis techniques [1-5]. Synthesis can be achieved by incorporating an active agent (e.g., antioxidant, enzyme, antimicrobial, oxygen scavenger) within or at the product contact surface of a packaging material. Positioning the active agent at the product contact side (versus bulk incorporation) has several benefits, including retention of bulk material properties and minimizing the amount (and therefore cost) of active agent required to impart efficacy. Understanding the technologies and challenges associated with various coating methods for preparation of active packaging materials will support effective technology transfer to commercial applications. The goal of this review is to describe key technologies for preparing active packaging coatings, including embedding, layer-by-layer deposition, and photografting, with a discussion of the difference between covalent (non-migratory) and non-covalent (migratory) immobilization chemistries. We then survey the current literature for active packaging technologies using these coating methods to impart antimicrobial, antioxidant, and biocatalytic activity. Smart/intelligent packaging [6,7], in which indicating devices are incorporated into the packaging structure, and sachet-based technologies [8] are well covered in the current literature and are outside the scope of this review. We conclude with a discussion of the challenges that remain in achieving commercial translation for active packaging coatings.

\section{Overview of Coating Technologies}

In the following subsections, the main approaches employed to prepare coatings for active packaging that have been reported in the literature are explained. These are the most frequent techniques found in the field of coatings for active packaging. Figure 1 shows a graphic summary of them.

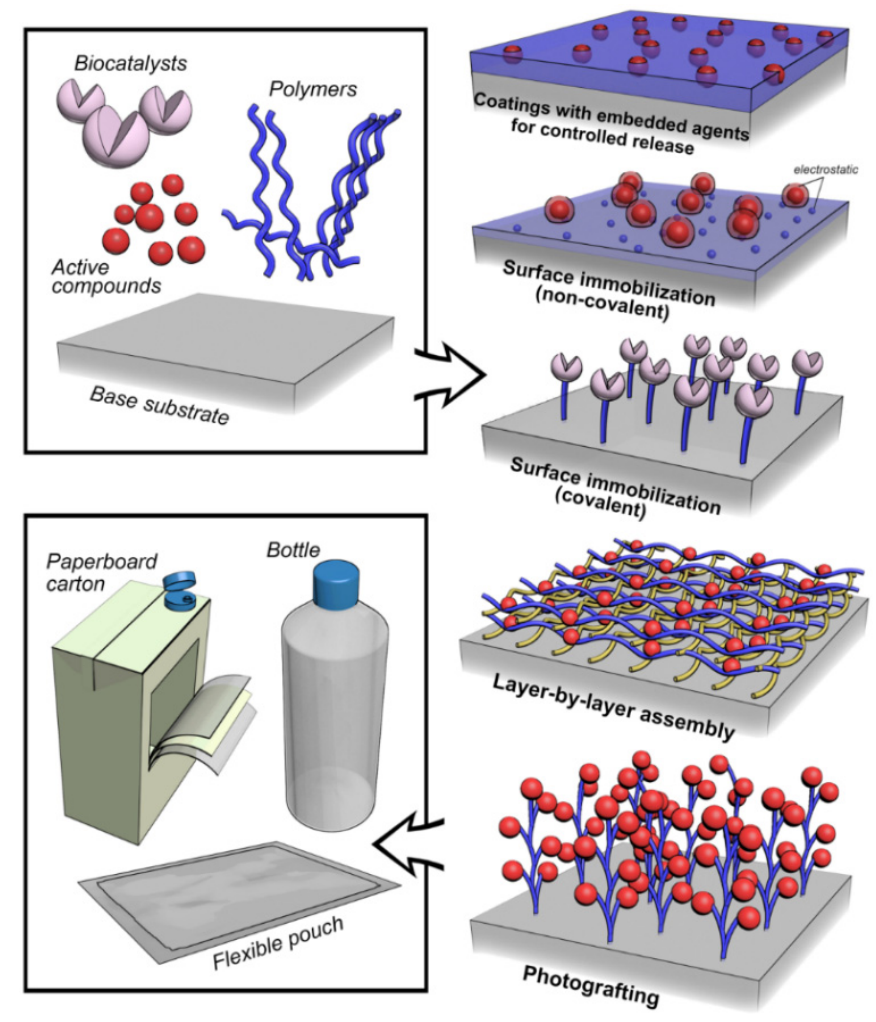

Figure 1. Summary of coating technologies. 


\subsection{Coatings with Embedded Agents for Controlled Release}

As illustrated in Figure 1, active agents can be incorporated into coatings for active packaging by a number of technologies, including those in which the active agent is intended to migrate to the packaged good (embedding, non-covalent immobilization, some layer-by-layer deposition techniques) and non-migratory technologies in which the active agent is intended to remain stable in the packaging matrix (covalent immobilization, some layer-by-layer deposition techniques, photografting). Controlled release coatings are those in which active agents have been incorporated into the matrices of polymeric materials, from which they are expected to migrate and exert their specific function within a packaged good, whether antimicrobial, antioxidant, biocatalytic, or neutraceutical [6]. The main reported mechanisms through which active compounds have been incorporated into polymeric materials have been extrusion/blending and solution casting $[9,10]$. Solution casting consists of dissolving the polymer intended for packaging in a suitable solvent and simultaneously incorporating the active compound of interest, followed by pouring the solubilized polymer and active agent onto a surface for the solvent to evaporate, resulting in formation of plastic film with targeted functionality (antimicrobial, pharmaceutical, biocatalytic, etc.). In extrusion, the active compound is incorporated with polymeric material melted by heat transfer forming a blend from which films can be formed. The first method, although extensively used at a laboratory scale, exhibits some limitations for its practical and commercial application as most of the polymers intended for food packaging can only be dissolved at high temperatures with organic solvents [11], which would compromise the stability and effectiveness of many active compounds of interest. This is probably the main reason why incorporation of active compounds through solution casting has been studied more frequently with biodegradable polymers that can be dissolved at milder temperatures, for example poly(lactic acid), poly(butylene adipate-co-terephtalate), and cellulose derivatives [9]. Extrusion and blending, although industrially scalable, can present serious limitations due to the intrinsic lack of thermal stability of many active compounds, which can be lost through degradation and evaporation during the heat transfer these unit operations involve [3,9]. Ensuring uniform distribution of the active compound and retaining thermomechanical film properties are additional challenges to preparation of extruded active packaging materials. Controlled release can rely on physical and chemical phenomena, like the degree of affinity between the active compound and the matrix of the packaging material, as well as its morphology and porosity, which if low could allow a slower release [3,9,12]. In addition, controlled release can be provided by a multilaminated system in which the layer that harbors the active compound is covered by an adjacent layer that could serve as a barrier that controls the rate of release of such compound $[9,13]$. Temperature also plays a relevant role in the release of active compounds embedded in polymer packaging materials. It has been observed extensively that diffusion increases with temperature, which could represent an advantage specifically for the case of antimicrobial packaging as microorganisms also reproduce faster with an increase in temperature $[9,13]$. However, even if after incorporation of the compound of interest its activity and effectiveness is demonstrated at a laboratory scale, it is well known that the incorporation of a foreign compound into the matrix of a plastic material (even at small concentrations, at which no activity may be observed) can substantially affect its properties relevant to processing, production and machinability. These include the tensile and mechanical properties (tensile strength, elastic modulus, elongation at break, etc.), the thermal properties (melting point, glass transition temperature, crystallization temperature, heat capacity, etc.), and the gas 
barrier properties (water vapor permeability, $\mathrm{O}_{2}$ and $\mathrm{CO}_{2}$ permeability, etc.) $[9,14]$. As the goal of active packaging is to enhance material performance, losing desirable material properties as a result of active agent incorporation limits commercial applicability. There is therefore an interest in the application of thin coatings rather than bulk modifications, as thin coatings are not expected to affect relevant physical and chemical properties [15]. Nevertheless, a major benefit of embedding active agents into a packaging film by coating or coextrusion is their use of currently available converting equipment.

\subsection{Surface Immobilization}

In addition to embedding, active packaging materials can be prepared by immobilization of an active agent on the surface of a bulk packaging material. Although less studied as a material for active packaging, paperboard can be functionalized to immobilize active compounds by modifying the chemistry of its main component cellulose, with the formation of reactive groups like aldehydes, epoxy, carboxylic acids, etc. [16]. More commonly reported is the surface modification of polymer materials for use in active packaging. Polymer packaging materials are typically inert, and require an initial functionalization to enable immobilization of an active agent. Surface activation techniques of plastic polymer substrates can be divided into physical and wet methods. Physical methods include flame, corona discharge, UV radiation, and plasma [5,15,17]. Wet methods involve the use of corrosive liquids to which the polymer substrates are directly exposed, like piranha solution (dissolved hydrogen peroxide and sulfuric acid), combined sodium hydroxide and sulfuric acid, chromic acid, potassium permanganate, and nitric acid [18-22]. The main effect of these surface activation methods is the formation of reactive oxygenated species on the polymer surface like carbonyl, hydroxyl and carboxylic acid groups [21,22]. Some methods of industrial relevance to activate the surface of polymeric packaging materials are flame, corona, and atmospheric or vacuum plasma [23], which remove contaminants from the surface of polymer films, increase their surface energy and wettability (in order to apply coatings of different types, like inks for printing or metallic coatings), and increase the level of oxygen on their surface. In contrast to the wet methods, the physical methods are more widely used due to their industrial scalability, given the fact that no liquid reagents of any kind are needed in their application, avoiding accumulation and handling of harmful waste [22]. Once a polymeric surface has been functionalized and the mentioned oxygen-containing moieties haven been incorporated on it, compounds of different functionality can be applied through either covalent or non-covalent immobilization. Non-covalent binding relies mainly on electrostatic interactions and affinity [22]. In the first case, the polymer surface possesses a certain net charge which can attract molecules with an opposite net charge. The second case refers to specific ligand-receptor interactions, like in the case of biotin-avidin [24]. Covalent immobilization as its name implies involves the covalent coupling of the active compound of interest onto the polymer surface. A potential benefit of covalent immobilization is that the active compound is not expected to migrate to the packaged product matrix, which could otherwise compromise its commercial application [22]. Active agents can be covalently linked directly to the polymer surface or by use of a crosslinker, which may either share a permanent covalent bond with both the polymeric substrate and the bioactive compound, or may promote covalent bond formation between the activated substrate and the bioactive compound without forming part of that link ("zero-length" crosslinkers) $[22,25]$. The covalent attachment between a polymeric surface and an active compound relies mainly on the formation of amide, ether, ester, and 
thioether bonds, created between the hydroxyl, amine, imine, carboxylic acid, and thiol groups the active compounds of interest may possess intrinsically (or are incorporated in their structure) and the functional groups created on the substrate $[22,25,26]$. A benefit to immobilization technologies is the potential versatility: once functional groups are introduced to the polymer surface, a range of bioactive agents (e.g., enzymes, peptides) can be immobilized through standard bioconjugation techniques.

\subsection{Layer-by-Layer Assembly}

Layer-by-layer assembly is a versatile method of surface modification that relies on the deposition and mutual attraction of alternating polyelectrolytes with opposite net charges onto a solid support [27,28]. A polymeric substrate can be made reactive through the previously explained methods of surface activation, imparting a certain charge on it, or a polyelectrolyte can be covalently attached onto its surface to further apply the alternate polyelectrolyte layers. The polyelectrolytes can be polymers of any kind (proteins, polysaccharides, synthetic polymers, etc.) that harbor a net charge, and they can be modified by the incorporation of functional groups to facilitate their deposition [27-29]. Deposition can be accomplished either by submersion of the substrate into polyelectrolyte solutions or by spraying of solutions onto the substrate; both techniques have potential for scalability as high throughput coating technologies. The deposition of the polyelectrolytes can be optimized by adjusting the $\mathrm{pH}$ of their solutions to a point of full protonation or deprotonation, to maximize the presence of charge [30]. The deposition can rely exclusively on electrostatic interactions [29,31], or covalent bonds can be built between the alternating layers through the use of crosslinkers [25,29,32,33]. Although theoretically an indefinite number of polyelectrolyte layers can be applied on a substrate [15], a state of saturation can be reached in which no more polyelectrolytes will deposit [32]. There seems to be a positive association between molecular weight of the polyelectrolytes and the thickness and stability of the system [32,34], although the type of bonds that hold together the layers (when covalently bound) and their likelihood to undergo hydrolysis under different environmental conditions also dictates stability [32]. Layer-by-layer deposition can be used to prepare active packaging coatings by the incorporation of active agents either between layers or within the structure of an individual polyelectrolyte. Pilot scale layer-by-layer deposition tools have been developed, suggesting the potential for scalability to high through put production of active packaging coatings via layer-by-layer deposition [35].

\subsection{Photografting}

In photografting, polymer chains are grafted from a surface by exposure to UV light in the 315-400 nm range in the presence of photoinitiators and monomers [36]. UV irradiation generates free radicals on the polymeric surface after which photoinitiators, reactive compounds that generate unpaired electrons upon UV light exposure, initiate polymerization of monomers [28]. Photografting may take place through three types of mechanisms: hydrogen abstraction, electron transfer, and cleavage [37]. In hydrogen abstraction, the energy provided by the UV light removes a hydrogen atom from a substrate (either from a hydrocarbon, an alcohol, or an ether), which leaves unpaired electrons on its surface. At the same time, the ketone group of a photoinitiator undergoes reduction by coupling with the removed hydrogen from the substrate and coupling its unpaired electron to the unpaired electrons on the substrate, which is followed by polymerization of any monomer of interest. In electron transfer, the carbonyl group 
of the photoinitiator is also reduced in an electron acceptor-donor system, in which an aminated compound (normally a tertiary amine, but secondary and primary amines can also take place in the reaction) provides the hydrogen from the $\alpha$ carbon of its structure. In the cleavage mechanism, the photoinitiator undergoes homolytic scission upon UV light exposure, which generates free radical species able to initiate polymerization between vinyl monomers. Some common photoinitiators are benzophenone [38], anthraquinone [37], thioxantone [37], and phenyl azide [39]. Polymeric photoinitiators have also been studied [37], as well as naturally derived photoinitiators like curcumin [40,41]. Photografting can be used to prepare active packaging coatings either by direct incorporation of the active agent during photografting, or by subsequent immobilization of the active compound after grafting of a polymer chain with reactive functional groups (e.g., acrylic acid).

\section{Applications}

There are a number of active agents that can be incorporated into or onto coatings for active packaging using the technologies described previously, as summarized in Table 1. Major classes of active agents include antimicrobials, antioxidants, and enzymes, with applications in active packaging coatings ranging from controlling microbial growth, inhibiting oxidative degradation reactions, and targeted biocatalysis. The nature of the bulk packaging material onto which the active coating is deposited varies, including materials such as polyethylene (PE), low density polyethylene (LDPE), polypropylene (PP), polyethylene terephthalate (PET), ethylene vinyl alcohol (EVOH), poly(lactic acid) (PLA), polyamide (PA), polystyrene (PS), polyvinyl alcohol (PVOH), etc. Much of the published and commercialized research on active packaging coatings has targeted food packaging applications, largely for maintaining safety and quality and controlling spoilage. While the focus of the applications surveyed below is largely on food applications, these technologies have relevance to packaging of consumer products (e.g., health and beauty) as well as pharmaceuticals and biomedical devices. Smart packaging intended for monitoring of temperature, oxygen, $\mathrm{pH}$, moisture, etc. [42,43] of packaged products represents a promising area for active packaging coatings, but falls outside the scope of this review.

\subsection{Antimicrobial}

Probably the most studied application of active packaging technologies has been antimicrobial packaging to control growth of pathogenic and/or spoilage microorganisms in packaged products. Antimicrobial agents such as essential oils, organic acids, peptides, enzymes, and biopolymers have been introduced into antimicrobial active packaging by a range of coating technologies. Regarding controlled release, a European patent describes a liquid formulation composed of essential oils, adhesion promotors (e.g., acrylic or vinyl resins or nitrocellulose), and fixatives to modulate the release of the essential oils for application on common packaging materials [44]. A recent study by Manso et al. demonstrated the anti-fungal character of the patented coating [45], in which a $30 \mu \mathrm{m}$ thick coating containing cinnamon essential oil (coating grammage of $2.5 \mathrm{~g} \cdot \mathrm{m}^{-2}$, with essential oil concentrations of $2 \%, 4 \%$ and $6 \%$ ) was applied to PP and evaluated against different species of Aspergillus and Penicillium. Seeded agar was exposed to coated films at a distance normally given between the agar surfaces and Petri dish lids, and it was observed that total inhibition was obtained at $4 \%$ and $6 \%$ concentrations for all the fungi evaluated regardless of temperature and $\mathrm{pH}$. In another work also involving controlled release of thyme and 
oregano essential oils [46], Valderrama Solano et al. reported coating onto corona treated LDPE films at concentrations of $1 \%$ and $4 \%$ (based on the weight of LDPE). Antimicrobial activity was demonstrated by zone of inhibition assays against Escherichia coli 0157:H7, Salmonella Typhimurium and Listeria monocytogenes, showing substantial inhibition at a concentration of $4 \%$ for all the pathogens, and no inhibition at $1 \%$ concentration. The authors further demonstrated that the reported coating method had not significant changes in the film mechanical properties (tensile strength and elongation at break) and although the changes in barrier properties (oxygen and water vapor transmission rates) were significant, they were probably not relevant enough to compromise their usage since a reduction in both parameters was observed. Another approach for controlled release involves the application of the sol-gel technique, which consists of the condensation of hydroxylated monomers and polymers into a network that can harbor active substances [47]. Lantano et al. recently reported on the preparation of a sol-gel coating in which the antifungal agent natamycin was embedded in a tetraethyl orthosilicate/EVOH gel and applied to plasma treated PLA films [48]. The natamycin loaded PLA films demonstrated release rates that were in accordance to European standards and were able to inhibit mold growth on cheese stored for 30 days at $4{ }^{\circ} \mathrm{C}$. In another study, Zhu et al. showed the potential to apply antimicrobial photocatalysts (e.g., $\mathrm{TiO}_{2}$ ) using the sol-gel technique [49].

Table 1. Summary of technologies and applications in active packaging coatings.

\begin{tabular}{|c|c|c|c|}
\hline \multirow{2}{*}{ Coating Technology } & \multicolumn{3}{|c|}{ Application } \\
\hline & Antimicrobial & Antioxidant & Biocatalytic \\
\hline \multirow{7}{*}{ Controlled release } & Essential oils $[45,46]$ & Citrus oil $[50-52]$ & Lactase [53] \\
\hline & Natamycin [48] & Rosemary extract [54] & Laccase [55] \\
\hline & $\mathrm{TiO}_{2}[49]$ & $\alpha$-tocopherol [56] & Oxalate oxidase [57] \\
\hline & Cinnamaldehyde [58] & - & - \\
\hline & Sorbic acid and lauric arginate ester [59] & - & - \\
\hline & Lauric arginate ester $[60]$ & - & - \\
\hline & Nisin [61] & - & - \\
\hline \multirow{4}{*}{ Immobilization } & 3-aminopropyltrimethoxysilane [62] & Gallic acid [63] & Lactase $[64,65]$ \\
\hline & Lysozyme $[66]$ & Aluminum oxide [67] & Catalase [68] \\
\hline & (3-bromopropyl)triphenylphosphonium [69] & - & Naringinase [70-72] \\
\hline & $\mathrm{SO}_{2}[73]$ & - & - \\
\hline Layer-by-layer & Chitosan $[74,75]$ & Tannic acid [76] & Lactase [77] \\
\hline assembly & Lysozyme [78] & - & - \\
\hline \multirow{3}{*}{ Photografting } & - & Caffeic acid [79] & Trypsin $[80-82]$ \\
\hline & - & Acrylic acid [83-85] & Urease [86] \\
\hline & - & Hydroxamic acid $[87,88]$ & - \\
\hline
\end{tabular}

There have been several reports in which controlled release coating technologies have been combined with surface immobilization to prepare antimicrobial coatings. In a recent study [58], Makwana et al., covalently attached polydiacetylene liposomes containing cinnamaldehyde onto an amine-functionalized silane monolayer on piranha treated glass. The authors also explored immobilizing the liposomes on amine-functionalized PLA films. Approximately three logarithmic reductions were obtained against Escherichia coli after $50 \mathrm{~min}$ of exposure to the liposome-encapsulated cinnamaldehyde (for both glass and poly(lactic acid)). For the case of Bacillus cereus, PLA was more effective ( 4 logarithmic 
reductions) than glass ( $\sim 3$ logarithmic reductions). What may be remarkable about this study is that it suggests the possibility of applying an approach for controlled release of antimicrobial substances on both organic and inorganic substrates. In another study, Guo et al. reported the direct coating of PLA with a mixture of chitosan (a widely studied polycation with known antimicrobial activity), sorbic acid, sodium lactate, and lauric arginate ester [59]. Antimicrobial effectiveness was confirmed both in bacterial suspensions (to an undetectable level for all microorganisms) and on ready to eat meat against Listeria innocua (2-3 logarithmic reductions), Listeria monocytogenes (2-3 logarithmic reductions) and Salmonella Tiphymurium (1-1.5 logarithmic reductions) under storage at $10{ }^{\circ} \mathrm{C}$. In other work [60], Theinsathid et al. spray coated corona treated PLA with solutions having varying concentrations of lauric arginate ester $(0 \%-10 \%)$. Between two and three logarithmic reductions were reached against Listeria monocytogenes and Salmonella Tiphymurium in wrapped ham samples after seven days of storage at $4{ }^{\circ} \mathrm{C}$ under the lowest antimicrobial concentration tested $(0.07 \%$ based on the weight of PLA). The authors demonstrated that the coating treatment did not affect the mechanical properties of poly(lactic acid); however, the gas barrier properties measured as $\mathrm{CO}_{2}$ permeation were adversely affected. In another work, the antimicrobial peptide nisin was entrapped in polyethylene oxide brushes grown on silane modified silicon wafers [61]. It was hypothesized that the polyethylene oxide brushes would protect nisin from being eluted by foreign proteins and subsequently losing its activity. Antimicrobial activity of the modified silicon wafers was confirmed through zone of inhibition assay against the Gram positive bacterium Pediococcus pentosaceous over a period of seven days. Retention of antimicrobial activity even after introduction of bovine serum albumin to the agar media supported their hypothesis that the polyethylene oxide brushes protected nisin. Although this coating was tested on an inorganic substrate, the authors proposed its potential for application on polymer packaging films.

Preparation of antimicrobial active coatings via covalent immobilization of antimicrobial agents is probably the least studied approach explored for antimicrobial packaging applications, likely because the most commonly studied antimicrobial agents (e.g., nisin, essential oils) must migrate from the packaging material to be effective. Cationic polymers and some antimicrobial enzymes, however, may retain efficacy after covalent immobilization onto a solid support. The cationic property of amines was tested in a study by Fernandes et al., in which pullalan powder was rendered cationic by reaction with an amine terminated silane, after which films were formed by solution casting [62]. The cationic pullalan films demonstrated more than three logarithmic reductions Staphylococcus aureus and Escherichia coli. In addition, the cationic pullulan films showed improved mechanical and thermal properties as compared to unmodified pullulan. In recent work by Muriel-Galet et al, the antimicrobial enzyme lysozyme was covalently attached onto UV-ozone treated EVOH films via carbodiimide chemistry and reported more than one logarithmic reduction of Listeria monocytogenes in bacterial suspension [66]. In another work, Anthierens et al. tested the possibility of functionalizing the flexible polymer poly(butylene adipate-co-terephtalate) with a quaternary phosphonium compound, (3-bromopropyl)triphenylphosphonium [69]. For that purpose, the biodegradable polymer was modified to introduce alkyne bonds to enable an azide-alkyne "click" reaction with the quaternary compound. The modified polyester was challenged against Escherichia coli both in bacterial suspension and under direct contact, reaching 4 logarithmic reductions after $1 \mathrm{~h}$ in bacterial suspension and after $24 \mathrm{~h}$ under direct contact. In another recent study by Mackiw et al. [73], a multilayered film made of PA and PE was subjected to atmospheric plasma treatment $\left(\mathrm{Ar}, \mathrm{Na}_{2} \mathrm{O}\right.$ and $\mathrm{SO}_{2}$ ) on the PA side of the films. $\mathrm{Na}_{2} \mathrm{O}$ 
was applied either alone with $\mathrm{Ar}$ or combined with $\mathrm{Ar}$ and $\mathrm{SO}_{2}$. The temperature for $\mathrm{Na}_{2} \mathrm{O}$ sublimation in the reactor was varied from $300-640{ }^{\circ} \mathrm{C}$. It was observed that the highest inhibitions were obtained from films possessing the highest concentrations of $\mathrm{SO}_{2}$ (the antimicrobial agent) against Escherichia coli (82\%), Staphylococcus aureus (86\%), Listeria monocytogenes (63\%), Bacillus subtilis (79\%), and Candida albicans (75\%). Even though less than one logarithmic reduction was reached for every microorganism, this type of approach seems promising due to its potential industrial scalability, as plasma treatment is a widely used method of surface activation for food packaging films [23].

The possibility of using the layer-by-layer approach has been explored through several studies. In one recent work published by Pinheiro et al., $\kappa$-carrageenan (polyanion) and chitosan (polycation) were applied onto aminated PET resulting in improved gas barrier properties (reduced oxygen and water vapor transmission rates) [74]. In other work presented by Carneiro-da-Cunha et al. [75], alginate was employed as the polyanion, suggesting it as an attractive alternative as there was not significant difference in water vapor permeability between the aminated PET film used and its coated counterpart. Finally, Medeiros et al., have reported on layer-by-layer deposition of three layers of $\kappa$-carrageenan alternated with two layers of the antimicrobial enzyme lysozyme on amine-functionalized PET films [78]. The modified PET exhibited improved values of oxygen and water vapor permeability as compared to aminated PET. To date, layer-by-layer deposition technologies have largely focused on improving barrier properties, but those described above incorporate components with antimicrobial character, suggesting their potential application in antimicrobial active packaging coatings. While antimicrobial active packaging technologies have focused largely on inhibiting microbial growth or inactivating viable organisms, there may be opportunity in adapting food processing equipment coatings technologies which seek to inhibit microbial adhesion.

\subsection{Antioxidant}

Oxidative degradation is a key limiting factor in overall shelf life of many food and consumer products, as well as nutritional supplements. Many packaged products undergo quality deterioration during transport and storage due to oxidative reactions that cause lipid rancidity (e.g., mono and polyunsaturated fatty acids), color loss (e.g., carotenoids, chlorophyll, anthocyanins), and vitamin degradation (e.g., Vitamin A and its precursors, Vitamin C, Vitamin D, Vitamin E). There are several preservation strategies for packaged goods that contain oxidation-sensitive ingredients based on direct addition of antioxidants (e.g., free radical scavengers, metal chelators, singlet oxygen quenchers, oxygen scavengers) and design of appropriate packaging systems. One such preservation strategy is antioxidant active packaging, wherein an antioxidant has been incorporated into a packaging material to enhance food preservation [14]. The most widely used commercially available antioxidant active packaging technologies include oxygen scavengers, manufactured as sachets or labels [89]. However, there is emerging research in the development of migratory and non-migratory antioxidant coatings for active packaging, as surveyed in this section.

Migratory antioxidant active coatings are designed for controlled release of an antioxidant over the course of product shelf life. The majority of research for antioxidant active packaging that is designed for controlled release has been focused on blending of antioxidants with polymers followed by extrusion [4,90]. However, inclusion of antioxidants in packaging may have a negative impact on bulk 
material properties that may limit applications. Research in the design of active coatings for controlled release of antioxidant is promising for overcoming this challenge. Corlini et al. prepared antioxidant packaging materials by spray deposition of citrus oil in methanol onto the surface of PET trays and observed that plasma pretreatment enhanced the adhesion of citrus oil to the surface of PET trays, which demonstrated higher overall antioxidant activity [50]. This coating exhibited antioxidant activity with cooked turkey meat and retained activity after six months of storage [51,52]. Bolumar et al. coated rosemary extract directly onto LDPE plastic wrap $\left(0.45 \mathrm{mg}\right.$ rosemary $\left.\mathrm{cm}^{-2}\right)$ and demonstrated significant delay in the onset of surface lipid oxidation of wrapped chicken patties. Controlled released of migratory antioxidant coatings may be enhanced by using a polymeric carrier for antioxidants rather than direct surface application [54]. For example, Lee et al. applied $\alpha$-tocopherol to paperboard using a vinyl acetate-ethylene copolymer as a carrier for controlled release $\left(D=2.91 \times 10^{-11} \mathrm{~m}^{2} \cdot \mathrm{s}^{-1}\right)$ and demonstrated its ability to retard oxidation in an oil-in-water emulsion [56].

Non-migratory antioxidant coatings are designed to scavenge prooxidants, such as free radicals, oxygen and transition metals, to extend the shelf life of oxidation-sensitive foods. Garces et al. patented an antioxidant coating composed of a polymer blend that contains plant extracts that scavenge free radicals [91]. Tovar et al. demonstrated that this antioxidant coating may be classified as non-migratory as it demonstrated migration that was 20 times less than the legal limits for the European Union [92]. Furthermore, this antioxidant active packaging coating derives activity from free radical scavenging in the packaging headspace, thus not requiring direct contact with the food [93-95]. Shutava et al. imparted free radical scavenging properties on glass slides via layer-by-layer deposition of tannic acid and poly(allylamine hydrochloride) and found that 2,2'-azino-bis(3-ethylbenzothiazoline-6-sulphonic acid) (ABTS) radical scavenging activity per mole immobilized tannic acid decreased with increasing number of bilayers, most likely due to inability of ABTS to diffuse through bilayers [76]. However, increasing the number of bilayers did result in a linear increase in overall scavenging activity (mol ABTS $\mathrm{cm}^{-2}$ ). There has also been significant research on metal oxide coatings that have been applied to packaging materials to reduce oxygen diffusion into packaging to extend shelf life [67,96].

Non-migratory antioxidant coatings may also be applied by covalent immobilization of functional groups to the surface of packaging materials. Gallic acid was immobilized to chitosan by carbodiimide assisted reaction that resulted in an active packaging material that demonstrated significant reduction in oxidation of ground peanuts [63]. In other work, Arrua et al. utilized photoinitiated graft polymerization of a polymer functionalized with caffeic acid to coat polypropylene packaging materials and demonstrated its ability to prevent oxidative degradation of ascorbic acid in orange juice [79]. Photoinitiated graft polymerization has also been used to fabricate metal chelating active packaging coatings that extended the lag phase of lipid oxidation in oil-in-water emulsions by chelating transition metals, which are the most influential prooxidants in food emulsions [83,87]. Further research in this area demonstrated that active packaging coatings composed of photografted polyhydroxamate chelators retain activity in a wide range of $\mathrm{pH}$ values (3-5), viscosity $\left(\sim 1-10^{4} \mathrm{CP}\right)$ and competing ion $(\mathrm{Na}, \mathrm{Mg}, \mathrm{Ca})$ conditions typically found in food and consumer products [97]. In addition to potential "clean label" regulatory benefits of non-migratory antioxidant coatings, such technologies have product quality advantages over migratory antioxidant packaging coatings, as migratory antioxidant coating technologies typically use active agents which must be used at a concentration which alters sensory perception (flavor, color, 
viscosity) of the packaged product. Nevertheless, technical hurdles remain in adapting non-migratory active coatings for commercial application.

\subsection{Biocatalytic}

The partnership of enzymes and solid support materials provides many opportunities for biocatalytic coatings for active packaging. Enzymes are proteins with enhanced specificity to a substrate, which catalyze reactions by lowering their activation energy to create products. Enzymes are employed in numerous processes used in the food, pharmaceutical, and diagnostic industries. In food processing, biocatalysts are used in production of ingredients, enhancement of product quality, and breakdown of undesirable components that may be harmful or may decrease product quality [98]. As the working conditions for biocatalytic materials can be very specific and variable with the immobilization method and material, there is much research on the immobilization of enzymes onto and into solid supports in order extend their thermostability, $\mathrm{pH}$ optima, and solvent stability. Integrating biocatalysts into packaging materials facilitates their use as active packaging coatings [99] which may enable so-called "in-package processing" where food constituents undergo changes to improve quality or shelf-life while in transport and storage.

The goal of many biocatalytic active packaging technologies is to control the growth of spoilage and/or pathogenic microorganisms. Lysozyme is a commonly utilized enzyme for such antimicrobial active packaging. Such antimicrobial enzymes have been incorporated into active packaging coatings via blending, non-covalent binding for controlled release, and covalent immobilization [100-102]. For additional information, refer to the comprehensive section on antimicrobial coatings of this review. Herein outlines methods for the incorporation of enzymes into biocatalytic coatings for active packaging, and a few works which have the potential for application in active packaging coatings.

Incorporation of enzymes into active packaging coatings by embedding and blending requires compatibility between the enzyme and the coating matrix. Compatibility can be achieved by surface functionalization, altering bulk material composition, and enzyme modification. Embedding and blending may simplify commercialization and scale-up as one-pot preparation methods become more available [16]; however, these techniques typically result in the enzyme becoming a part of the packaged product, reducing catalytic activity of the coating over time [103]. A targeted application for several biocatalytic active packaging coatings technologies involves the removal of oxygen for increased food shelf stability. Efforts towards incorporation of glucose oxidase in a low-density polyethylene and paper board multilaminate have included details for scaled-up production. Various compositions of LDPE, glucose oxidase, and catalase were produced in Tetra Pak's pilot plant, and showed up to 97\% activity could initially be achieved even after exposure to $325{ }^{\circ} \mathrm{C}$ during production. Control of production parameters was key to maintaining the package's oxygen scavenging capability [104]. Johansson et al. worked to improve embedding the glucose oxidase and catalase oxygen scavenging pair by varying combinations of LDPE, polypropylene, and polylactic acid [55]. Variations of these embedding methods for oxygen scavenging by laccase and oxalate oxidase have shown similar results [55,57]. Recent work by Talbert et al. demonstrates that enzymes may be modified by hydrophobic ion pairing to be soluble and retain activity in solvents used in ink formulations, enabling the preparation of biocatalytic active packaging coatings using existing printing technology [105]. 
Much of the work on biocatalytic coatings for food packaging involves covalent immobilization. Covalent immobilization allows for biocatalytic coatings to interact with packaged products without being incorporated into the food matrix, enabling their regulation as contact materials rather than direct additives. Non-migratory biocatalytic coatings therefore offer a potential regulatory benefit, as there is growing demand for "clean label" products. For example, Soares and Hotchkiss developed non-migratory packaging films to de-bitter fruit juices by covalently immobilizing fungal naringinase [70,71]. Naringinase activity was maintained for 15 days storage after preparation of the biocatalytic active packaging coating, and $k_{M}$ values were lower when compared to free enzyme. Nunes et al., achieved similar success by cross-linking naringinase to polyvinyl alcohol and alginate using boric acid for de-bittering [72]. In other work, $\beta$-galactosidase was bound to amine-functionalized polyethylene films by a dialdehyde tether to reduce milk lactose in package [64]. Further research demonstrated that tether length and chemistry can influence retained activity of immobilized lactase [65], but more significant enhancements in retained activity can be achieved by immobilization onto nanostructures [106].

Layer-by-layer deposition allows for more enzyme to be incorporated in a biocatalytic coating compared to traditional immobilization techniques. Indeed, increasing the number of functional layers increases total protein content. Biocatalytic coatings prepared by layer-by-layer deposition of polyethylenamine, glutaraldehyde, and lactase exhibited increased protein loading with each layer [77]. However, overall activity did not increase with layers, likely a result of reduced substrate accessibility by enzyme entrapped in sub-interfacial layers. In other work, Shutava et al. layered hemoglobin, PS, and catalase in order to create a physical and chemical protective barrier [68]. Although the layer-by-layer technique has been shown to increase protein loading, diffusion of substrate to enzyme can become difficult. Increasing substrate diffusion through formed layers would improve activity retention, and therefore commercial potential, of biocatalytic coatings prepared by layer-by-layer deposition.

Photografting is often used in combination with other surface modification methods for preparation of biocatalytic coatings. Garnett et al. published an early report on immobilization of the protease trypsin to PP, PVOH, and PS by enhancing photografting with the use of metal salts [80]. Carboiimide chemistry can be used to covalently couple enzymes (via amine groups) to carboxylic acid groups introduced to a material surface via photografted polymerization [81]. Krenkova et al., functionalized poly(ethylene) glycol methacrylate to immobilize trypsin and endoproteinases for antibody analysis in enzyme reactors. In that work, 4-vinyl-2,2-dimethylazolactone was photografted to introduce a porous surface morphology with the goal of optimizing enzyme orientation to improve performance. As a result, non-specific protein binding was reduced and the protein substrate was successfully digested [82]. In other work, the hydrolase urease was immobilized to photgrafted polytetrafluoroethylene to remove urea from beverages and foods by Yamada et al., After immobilization, urease exhibited lowered activity at higher protein contents due to high protein densities as a result of grafted layers [86]. Indeed, a common challenge in enzyme immobilization is tailoring immobilization density and material chemistry to reduce adverse protein-protein and protein-surface interactions [107].

Emerging technologies in biocatalytic materials such as electrospun nanofibers and biopatterning offer new opportunities in preparing biocatalytic active packaging coatings. Electrospinning is a method by which enzymes or other active agents can be incorporated into polymer nanofibers. In one report, lactase blended into polyethylene oxide nanofibers retained up to $93 \%$ of free enzyme activity with significant retention of activity after dry storage [53]. In other work by Ge et al., glucose oxidase was 
immobilized onto electrospun polyvinyl acetate/chitosan/tea extract fibers to reduce oxygen in packaged foods to extend shelf life [108]. The immobilized glucose oxidase in this system retained over $68 \%$ of free enzyme activity. Drug delivery with controlled release has sparked new interest in various fiber morphologies, as well as micro and nanoparticles and hydrogels. Embedding and blending is often paired with cross-linking techniques to improve retention of the support material's physical properties [109]. Biopatterning, in which specific patterns of immobilized biomolecules are defined with micron or submicron resolution, also has potential application in active packaging coatings. For example, patterning cells to the interior of microfluidic channels by photografting poly(ethylene glycol) reduced non-specific protein binding [110,111]. Creating specific patterns for enzyme immobilization can focus activity on targeted regions in a packaging matrix, thereby reducing material waste during functionalization and controlling coating costs. Because of the interdependence of the enzyme structure on biocatalytic activity, preparation of biocatalytic coatings demands a whole systems approach, with consideration given to the enzyme and the coating matrix as well as the packaged product. Consideration must be given to reducing diffusional limitations of substrate and product, as well as activity retention for increased thermostability and $\mathrm{pH}$ stability. The overall stability of the bound enzyme determines the success of the coating method.

\section{Challenges and Perspectives}

Exciting opportunities exist in the development of active packaging coatings for improving the safety, quality, and shelf life of packaged goods, which is brought about by an increasing preference and demand from consumers for additive-free foods and a continuously expanding transport chain and standards of quality driven by global commerce [112]. The global trade of active food packaging was estimated to be close to US $\$ 9,000,000,000.00$ in 2011 and it is expected to be around US \$12,000,000,000.00 in 2017 [113]. Nevertheless, the active food packaging market is currently widely dominated by oxygen scavenging and moisture absorption applications [112,114]. A number of challenges remain prior to the commercial adoption of the types of applications studied in this review. A key consideration in developing coatings for active packaging applications is considering toxicity and potential for regulatory approval of not just the active agent but any tether molecules or cross-linkers that may be employed [115]. Consideration must also be given to requirements of different regulatory agencies, whether under the jurisdiction of the Food and Drug Administration (in the United States), the European Food Safety Authority (in the European Union), or elsewhere. Non-migratory technologies produced by either covalent immobilization, cross-linked layer-by-layer deposition, or some photografted coatings offer a potential regulatory benefit in US regulated food packaging applications, as they would require approval as food contact materials rather than direct additives [116]. Migration testing using standardized simulants (water, 3\% acetic acid, $15 \%$ ethanol, olive oil, iso-octane, and $95 \%$ ethanol) must be performed to quantify levels of migrants in packaged product systems [117]. It is also critical to consider the influence of the active coating on other performance characteristics of the packaging material. A benefit to coatings over bulk material modification is that bulk material properties should remain intact. However, the influence of the coating on processability, thermomechanical properties, barrier properties, and seal strength must be characterized [118]. Rigorous application tests must also be performed to ensure that neither material conversion steps nor end use result in delamination of active coatings. Many of the coatings technologies 
surveyed in this report have potential for scalability to roll-to-roll, high throughput coating operations. Finally, while incorporation of active agents and specialized packaging processes will indeed increase material cost, the opportunities for new products, enhanced safety, and reduced waste of packaged goods highlight the potential for increasing product value through smart integration of active packaging coatings.

\section{Acknowledgments}

This material is based upon work supported by the National Institute of Food and Agriculture, U.S. Department of Agriculture, under project numbers 2012-67017-30157, 2011-65210-20059, 2014-67021-21584, and 2015-67017-23119. M.J. Roman would like to acknowledge the Peter Salmon Graduate Fellowship (Department of Food Science, UMass Amherst) and Northeast Alliance for Graduate Education and the Professoriate Fellowship for their support. D.E. Wong acknowledges Agriculture and Food Research Initiative Grant No. 2015-67011-22820 for NIFA Predoctoral Fellowship support.

\section{Author contributions}

Luis J. Bastarrachea wrote the overview of coating technologies and the antimicrobial applications sections and contributed to overall document formatting; Dana E. Wong wrote the biocatalytic applications part; Maxine J. Roman wrote the antioxidant applications section; Zhuangsheng Lin contributed the graphics and proofread the manuscript; and Julie M. Goddard wrote the challenges and perspectives section and edited the full text.

\section{Conflicts of Interest}

The authors declare no conflict of interest.

\section{References}

1. Appendini, P.; Hotchkiss, J.H. Review of antimicrobial food packaging. Innov. Food Sci. Emerg. Technol. 2002, 3, 113-126.

2. Vermeiren, L.; Devlieghere, F.; van Beest, M.; de Kruijf, N.; Debevere, J. Developments in the active packaging of foods. Trends Food Sci. Technol. 1999, 10, 77-86.

3. Suppakul, P.; Miltz, J.; Sonneveld, K.; Bigger, S.W. Active packaging technologies with an emphasis on antimicrobial packaging and its applications. J. Food Sci. 2003, 68, 408-420.

4. Tian, F.; Decker, E.A.; Goddard, J.M. Controlling lipid oxidation of food by active packaging technologies. Food Funct. 2013, 4, 669-680.

5. Ozdemir, M.; Floros, J. Active food packaging technologies. Crit. Rev. Food Sci. Nutr. 2004, 44, 185-193.

6. Yam, K.; Takhistov, P.; Miltz, J. Intelligent packaging: Concepts and applications. J. Food Sci. 2005, 70, R1-R10.

7. Kuswandi, B.; Wicaksono, Y.; Jayus; Aminah, A.; Heng, L.Y.; Ahmad, M. Smart packaging: Sensors for monitoring of food quality and safety. Sens. Instrum. Food Qual. Saf. 2011, 5, 137-146. 
8. Smith, J.P.; Hoshino, J.; Abe, Y. Interactive packaging involving sachet technology. In Active Food Packaging, 1st ed.; Rooney, M.L., Ed.; Springer: Berlin, Germany; Heidelberg, Germany, 1995; pp. 143-173.

9. Bastarrachea, L.; Dhawan, S.; Sablani, S.S. Engineering properties of polymeric-based antimicrobial films for food packaging. Food Eng. Rev. 2011, 3, 79-93.

10. Han, J.H.; Floros, J.D. Casting antimicrobial packaging films and measuring their physical properties and antimicrobial activity. J. Plast. Film Sheeting 1997, 13, 287-298.

11. Vasile, C. General survey of the properties of polyolefins. In Handbook of Polyolefins, 2nd ed.; Vasile, C., Ed.; Marcel Dekker: New York, NY, USA, 2000; pp. 401-416.

12. Min, S.; Krochta, J.M. Edible coatings containing bioactive antimicrobial agents. In Packaging for Nonthermal Processing of Food; Han, J.H., Ed.; Blackwell Publishing: Hoboken, NJ, USA; IFT Press: Ames, IA, USA, 2007; pp. 29-52.

13. Han, J.H. Antimicrobial food packaging. In Novel Food Packaging Techniques; Ahvenainen, R., Ed.; CRC Press: Boca Raton, FL, USA; Woodhead Pub. Ltd.: Cambridge, UK, 2003; pp. 50-65.

14. Robertson, G.L. Food Packaging: Principles and Practice, 2nd ed.; Taylor \& Francis/CRC Press: Boca Raton, FL, USA, 2006; p. 550.

15. Ratner, B.D. Surface modification of polymers: Chemical, biological and surface analytical challenges. Biosens. Bioelectron. 1995, 10, 797-804.

16. Kong, F.; Hu, Y.F. Biomolecule immobilization techniques for bioactive paper fabrication. Anal. Bioanal. Chem. 2012, 403, 7-13.

17. Chan, C.M.; Ko, T.M.; Hiraoka, H. Polymer surface modification by plasmas and photons. Surf. Sci. Rep. 1996, 24, 1-54.

18. Chatelier, R.C.; Xie, X.; Gengenbach, T.R.; Griesser, H.J. Quantitative analysis of polymer surface restructuring. Langmuir 1995, 11, 2576-2584.

19. Jansen, B.; Kohnen, W. Prevention of Biofilm Formation by Polymer Modification. J. Ind. Microbiol. 1995, 15, 391-396.

20. Sato, T.; Hiruma, K.; Shirai, M.; Tominanga, K.; Haraguchi, K.; Katsuyama, T.; Shimada, T. Site-controlled growth of nanowhiskers. Appl. Phys. Lett. 1995, 66, 159-161.

21. Barish, J.A.; Goddard, J.M. Topographical and chemical characterization of polymer surfaces modified by physical and chemical processes. J. Appl. Polym. Sci. 2011, 120, 2863-2871.

22. Goddard, J.M.; Hotchkiss, J.H. Polymer surface modification for the attachment of bioactive compounds. Prog. Polym. Sci. 2007, 32, 698-725.

23. Wagner, J.R, Jr. Multilayer Flexible Packaging Technology and Applications for the Food, Personal Care and Over-the-Counter Pharmaceutical Industries, 1st ed.; Elsevier Science: Oxford, NY, USA, 2010; p. 258.

24. Moy, V.T.; Florin, E.L.; Gaub, H.E. Intermolecular forces and energies between ligands and receptors. Science 1994, 266, 257-259.

25. Hermanson, G. Bioconjugate Techniques, 2nd ed.; Academic Press: Boston, MA, USA, 2008; p. 1202.

26. Farkaš, P.; Bystrický, S. Chemical conjugation of biomacromolecules: A mini-review. Chem. Pap. 2010, 64, 683-695. 
27. Decher, G. Fuzzy nanoassemblies: Toward layered polymeric multicomposites. Science 1997, 277, 1232-1237.

28. Ratner, B.D.; Hoffman, A.S. Physichochemical surface modification of materials used in medicine. In Biomaterials Science: An Introduction to Materials in Medicine, 3rd ed.; Ratner, B.D., Hoffman, A.S., Schoen, F.J., Lemons, J.E., Eds.; Academic Press: Oxford, UK; Waltham, MA, USA, 2013; pp. 259-276.

29. Bastarrachea, L.J.; Denis-Rohr, A.; Goddard, J.M. Antimicrobial food equipment coatings: Applications and challenges. Annu. Rev. Food Sci. Technol. 2015, 6, 97-118.

30. Yang, Y.; Haile, M.; Park, Y.T.; Malek, F.A.; Grunlan, J.C. Super gas barrier of all-polymer multilayer thin films. Macromolecules 2011, 44, 1450-1459.

31. Cerkez, I.; Kocer, H.B.; Worley, S.D.; Broughton, R.M.; Huang, T.S. N-Halamine biocidal coatings via a layer-by-layer assembly technique. Langmuir 2011, 27, 4091-4097.

32. Bastarrachea, L.J.; McLandsborough, L.A.; Peleg, M.; Goddard, J.M. Antimicrobial N-Halamine modified polyethylene: Characterization, biocidal efficacy, regeneration, and stability. J. Food Sci. 2014, 79, E887-E897.

33. Bastarrachea, L.J.; Peleg, M.; McLandsborough, L.A.; Goddard, J.M. Inactivation of Listeria Monocytogenes on a polyethylene surface modified by layer-by-layer deposition of the antimicrobial N-Halamine. J. Food Eng. 2013, 117, 52-58.

34. Haynie, D.; Zhang, L.; Rudra, J.; Zhao, W.; Zhong, Y.; Palath, N. Polypeptide multilayer films. Biomacromolecules 2005, 6, 2895-2913.

35. SPALASTM (Spray Assisted Layer-by-Layer Assembly) Coating System. Available online: http://www.agiltron.com (accessed on 20 September 2015).

36. Odian, G.G. Principles of Polymerization, 4th ed.; Wiley InterScience: Hoboker, NJ, USA, 2004; p. 812.

37. Carlini, C.; Angiolini, L. Polymers as free radical photoinitiators. In Synthesis and Photosynthesis; Springer-Verlag: Heidelberg, Germany, 1995; pp. 127-214.

38. Dunkirk, S.G.; Gregg, S.L.; Duran, L.W.; Monfils, J.D.; Haapala, J.E.; Marcy, J.A.; Clapper, D.L.; Amos, R.A.; Guire, P.E. Photochemical coatings for the prevention of bacterial colonization. J. Biomater. Appl. 1991, 6, 131-156.

39. Matsuda, T.; Inoue, K. Novel photoreactive surface modification technology for fabricated devices. ASAIO Trans. 1990, 36, 161-164.

40. Mishra, A.; Daswal, S. Curcumin, A Novel natural photoinitiator for the copolymerization of styrene and methylmethacrylate. J. Macromol. Sci. A 2005, 42, 1667-1678.

41. Zhao, J.; Lalevée, J.; Lu, H.; MacQueen, R.; Kable, S.H.; Schmidt, T.W.; Stenzel, M.H.; Xiao, P. A new role of curcumin: As a multicolor photoinitiator for polymer fabrication under household UV to red LED bulbs. Polym. Chem. 2015, 6, 5053-5061.

42. Brody, A.L.; Strupinsky, E.R.; Kline, L.R. Active Packaging for Food Applications; Technomic Pub. Co.: Lancaster, PA, USA, 2001; p. 218.

43. Kerry, J.; Butler, P. Smart Packaging Technologies for Fast Moving Consumer Goods; John Wiley: Chichester, UK; Hoboken, NJ, USA, 2008; p. 340.

44. Garces, L.O.; de la Puerta, C.N. Antimicrobial packaging based on the use of natural extracts and the process to obtain this packaging. European Patent EP1657181-B1, 13 January 2010. 
45. Manso, S.; Becerril, R.; Nerin, C.; Gomez-Lus, R. Influence of pH and temperature variations on vapor phase action of an antifungal food packaging against five mold strains. Food Control 2015, 47, 20-26.

46. Valderrama Solano, A.C.; Rojas de Gante, C. Two different processes to obtain antimicrobial packaging containing natural oils. Food Bioprocess Technol. 2012, 5, 2522-2528.

47. Minelli, M.; de Angelis, M.G.; Doghieri, F.; Rocchetti, M.; Montenero, A. Barrier properties of organic-inorganic hybrid coatings based on polyvinyl alcohol with improved water resistance. Polym. Eng. Sci. 2010, 50, 144-153.

48. Lantano, C.; Alfieri, I.; Cavazza, A.; Corradini, C.; Lorenzi, A.; Zucchetto, N.; Montenero, A. Natamycin based sol-gel antimicrobial coatings on polylactic acid films for food packaging. Food Chem. 2014, 165, 342-347.

49. Zhu, Y.; Buonocore, G.G.; Lavorgna, M. Photocatalytic activity of $\mathrm{PLA} / \mathrm{TiO}_{2}$ nanocomposites and $\mathrm{TiO}_{2}$-active multilayered hybrid coatings. Ital. J. Food Sci. 2012, 24, 102-106.

50. Contini, C.; Katsikogianni, M.G.; O’Neill, F.T.; O’Sullivan, M.; Boland, F.; Dowling, D.P.; Monahan, F.J. Storage stability of an antioxidant active packaging coated with citrus extract following a plasma jet pretreatment. Food Bioprocess Technol. 2014, 7, 2228-2240.

51. Contini, C.; Álvarez, R.; O’Sullivan, M.; Dowling, D.P.; Gargan, S.O.; Monahan, F.J. Effect of an active packaging with citrus extract on lipid oxidation and sensory quality of cooked turkey meat. Meat Sci. 2014, 96, 1171-1176.

52. Contini, C.; Katsikogianni, M.G.; O’Neill, F.T.; O’Sullivan, M.; Dowling, D.P.; Monahan, F.J. PET trays coated with citrus extract exhibit antioxidant activity with cooked turkey meat. LWT Food Sci. Technol. 2012, 47, 471-477.

53. Wong, D.E.; Dai, M.; Talbert, J.N.; Nugen, S.R.; Goddard, J.M. Biocatalytic polymer nanofibers for stabilization and delivery of enzymes. J. Mol. Catal. B Enzym. 2014, 110, 16-22.

54. Bolumar, T.; Andersen, M.L.; Orlien, V. Antioxidant active packaging for chicken meat processed by high pressure treatment. Food Chem. 2011, 129, 1406-1412.

55. Johansson, K.; Winestrand, S.; Johansson, C.; Jarnstrom, L.; Jonsson, L.J. Oxygen-scavenging coatings and films based on lignosulfonates and laccase. J. Biotechnol. 2012, 161, 14-18.

56. Lee, C.H.; An, D.S.; Lee, S.C.; Park, H.J.; Lee, D.S. A Coating for use as antimicrobial and antioxidative packaging material incorporating nisin and $\alpha$-tocopherol. J. Food Eng. 2004, 62, $323-329$.

57. Winestrand, S.; Johansson, K.; Järnström, L.; Jönsson, L.J. Co-immobilization of oxalate oxidase and catalase in films for scavenging of oxygen or oxalic acid. Biochem. Eng. J. 2013, 72, 96-101.

58. Makwana, S.; Choudhary, R.; Dogra, N.; Kohli, P.; Haddock, J. Nanoencapsulation and immobilization of cinnamaldehyde for developing antimicrobial food packaging material. LWT Food Sci. Technol. 2014, 57, 470-476.

59. Guo, M.; Jin, T.Z.; Yang, R. Antimicrobial polylactic acid packaging films against listeria and salmonella in culture medium and on ready-to-eat meat. Food Bioprocess Technol. 2014, 7, 3293-3307.

60. Theinsathid, P.; Visessanguan, W.; Kruenate, J.; Kingcha, Y.; Keeratipibul, S. Antimicrobial activity of lauric arginate-coated polylactic acid films against listeria monocytogenes and salmonella typhimurium on cooked sliced ham. J. Food Sci. 2012, 77, M142-M149. 
61. Auxier, J.A.; Schilke, K.F.; McGuire, J. Activity retention after nisin entrapment in a polyethylene oxide brush layer. J. Food Protect. 2014, 77, 1624-1629.

62. Fernandes, S.C.M.; Sadocco, P.; Causio, J.; Silvestre, A.J.D.; Mondragon, I.; Freire, C.S.R. Antimicrobial pullulan derivative prepared by grafting with 3-aminopropyltrimethoxysilane: characterization and ability to form transparent films. Food Hydrocoll. 2014, 35, 247-252.

63. Schreiber, S.B.; Bozell, J.J.; Hayes, D.G.; Zivanovic, S. Introduction of primary antioxidant activity to chitosan for application as a multifunctional food packaging material. Food Hydrocoll. 2013, 33, 207-214.

64. Goddard, J.M.; Talbert, J.N.; Hotchkiss, J.H. Covalent attachment of lactase to low-density polyethylene films. J. Food Sci. 2007, 72, E36-E41.

65. Mahoney, K.W.; Talbert, J.N.; Goddard, J.M. Effect of polyethylene glycol tether size and chemistry on the attachment of lactase to polyethylene films. J. Appl. Polym. Sci. 2013, 127, 1203-1210.

66. Muriel-Galet, V.; Talbert, J.N.; Hernandez-Munoz, P.; Gavara, R.; Goddard, J.M. Covalent immobilization of lysozyme on ethylene vinyl alcohol films for nonmigrating antimicrobial packaging applications. J. Agric. Food Chem. 2013, 61, 6720-6727.

67. Struller, C.F.; Kelly, P.J.; Copeland, N.J. Aluminum oxide barrier coatings on polymer films for food packaging applications. Surf. Coat. Technol. 2014, 241, 130-137.

68. Shutava, T.G.; Kommireddy, D.S.; Lvov, Y.M. Layer-by-layer enzyme/polyelectrolyte films as a functional protective barrier in oxidizing media. J. Am. Chem. Soc. 2006, 128, 9926-9934.

69. Anthierens, T.; Billiet, L.; Devlieghere, F.; du Prez, F. Poly(butylene adipate) functionalized with quaternary phosphonium groups as potential antimicrobial packaging material. Innov. Food Sci. Emerg. Technol. 2012, 15, 81-85.

70. Soares, N.F.F.; Hotchkiss, J.H. Bitterness reduction in grapefruit juice through active packaging. Packag. Technol. Sci. 1998, 11, 9-18.

71. Soares, N.; Hotchkiss, J. Naringinase immobilization in packaging films for reducing naringin concentration in grapefruit juice. J. Food Sci. 1998, 63, 61-65.

72. Nunes, M.A.P.; Vila-Real, H.; Fernandes, P.C.B.; Ribeiro, M.H.L. Immobilization of naringinase in PVA-alginate matrix using an innovative technique. Appl. Biochem. Biotechnol. 2010, 160, 2129-2147.

73. Mackiw, E.; Maka, L.; Sciezynska, H.; Pawlicka, M.; Dziadczyk, P.; Rzanek-Boroch, Z. The impact of plasma-modified films with sulfur dioxide, sodium oxide on food pathogenic microorganisms. Package Technol. Sci. 2015, 28, 285-292.

74. Pinheiro, A.C.; Bourbon, A.I.; Medeiros, B.G.D.S.; da Silva, L.H.M.; da Silva, M.C.H.; Carneiro-da-Cunha, M.G.; Coimbra, M.A.; Vicente, A.A. Interactions between $\kappa$-carrageenan and chitosan in nanolayered coatings-structural and transport properties. Carbohydr. Polym. 2012, 87, 1081-1090.

75. Carneiro-da-Cunha, M.G.; Cerqueira, M.A.; Souza, B.W.S.; Carvalhoc, S.; Quintas, M.A.C.; Teixeira, J.A.; Vicente, A.A. Physical and thermal properties of a chitosan/alginate nanolayered PET film. Carbohydr. Polym. 2010, 82, 153-159.

76. Shutava, T.G.; Prouty, M.D.; Agabekov, V.E.; Lvov, Y.M. Antioxidant properties of layer-by-layer films on the basis of tannic acid. Chem. Lett. 2006, 35, 1144-1145. 
77. Wong, D.E.; Talbert, J.N.; Goddard, J.M. Layer by layer assembly of a biocatalytic packaging film: Lactase covalently bound to low-density polyethylene. J. Food Sci. 2013, 78, E853-E860.

78. Medeiros, B.G.D.S.; Pinheiro, A.C.; Teixeira, J.A.; Vicente, A.A.; Carneiro-da-Cunha, M.G. Polysaccharide/protein nanomultilayer coatings: Construction, characterization and evaluation of their effect on "Rocha" pear (Pyrus communis L.) shelf-life. Food Bioprocess Technol. 2012, 5, 2435-2445.

79. Arrua, D.; Strumia, M.C.; Nazareno, M.A. Immobilization of Caffeic acid on a polypropylene film: Synthesis and antioxidant properties. J. Agric. Food Chem. 2010, 58, 9228-9234.

80. Garnett, J.L.; Jankiewicz, S.V.; Long, M.A.; Sangster, D.F. Radiation and photografting as complementary techniques for immobilizing bioactive materials. Int. J. Radiat. Appl. Instrum. C Radiat. Phys. Chem. 1986, 27, 301-309.

81. Yamada, K.; Nakasone, T.; Nagano, R.; Hirata, M. Retention and reusability of trypsin activity by covalent immobilization onto grafted polyethylene plates. J. Appl. Polym. Sci. 2003, 89, 3574-3581.

82. Krenkova, J.; Lacher, N.A.; Svec, F. Highly efficient enzyme reactors containing trypsin and endoproteinase LysC immobilized on porous polymer monolith coupled to MS suitable for analysis of antibodies. Anal. Chem. 2009, 81, 2004-12.

83. Tian, F.; Decker, E.A.; Goddard, J.M. Control of lipid oxidation by nonmigratory active packaging films prepared by photoinitiated graft polymerization. J. Agric. Food Chem. 2012, 60, 7710-7718.

84. Roman, M.J.; Tian, F.; Decker, E.A.; Goddard, J.M. Iron chelating polypropylene films: Manipulating photoinitiated graft polymerization to tailor chelating activity. J. Appl. Polym. Sci. 2014, 131, doi:10.1002/app.39948.

85. Tian, F.; Decker, E.A.; McClements, D.J.; Goddard, J.M. Influence of non-migratory metal-chelating active packaging film on food quality: Impact on physical and chemical stability of emulsions. Food Chem. 2014, 151, 257-265.

86. Yamada, K.; Iizawa, Y.; Yamada, J.; Hirata, M. Retention of activity of urease immobilized on grafted polymer films. J. Appl. Polym. Sci. 2006, 102, 4886-4896.

87. Tian, F.; Decker, E.A.; Goddard, J.M. Controlling lipid oxidation via a biomimetic iron chelating active packaging material. J. Agric. Food Chem. 2013, 61, 12397-12404.

88. Tian, F.; Roman, M.J.; Decker, E.A.; Goddard, J.M. Biomimetic design of chelating interfaces. J. Appl. Polym. Sci. 2015, 132, 1-8.

89. López-Rubio, A.; Lagarón, J.M.; Ocio, M.J. Active Polymer Packaging of Non-Meat Food Products; John Wiley \& Sons, Ltd.: West Sussex, UK, 2008; pp. 19-32.

90. Gomez-Estaca, J.; Lopez-de-Dicastillo, C.; Hernandez-Munoz, P.; Catala, R.; Gavara, R. Advances in antioxidant active food packaging. Trends Food Sci. Technol. 2014, 35, 42-51.

91. Garces, O.; Nerin, C.; Beltran, J.; Roncales, P. Antioxidant active varnish. European Patent EP1477159-A1, 22 December 2003.

92. Tovar, L.; Salafranca, J.; Sánchez, C.; Nerín, C. Migration studies to assess the safety in use of a new antioxidant active packaging. J. Agric. Food Chem. 2005, 53, 5270-5275.

93. Nerin, C.; Tovar, L.; Salafranca, J. Behaviour of a new antioxidant active film versus oxidizable model compounds. J. Food Eng. 2008, 84, 313-320. 
94. Pezo, D.; Salafranca, J.; Nerín, C. Design of a method for generation of gas-phase hydroxyl radicals, and use of HPLC with fluorescence detection to assess the antioxidant capacity of natural essential oils. Anal. Bioanal. Chem. 2006, 385, 1241-1246.

95. Pezo, D.; Salafranca, J.; Nerín, C. Determination of the antioxidant capacity of active food packagings by in situ gas-phase hydroxyl radical generation and high-performance liquid chromatography-fluorescence detection. J. Chromatogr. A 2008, 1178, 126-133.

96. Chatham, H. Oxygen diffusion barrier properties of transparent oxide coatings on polymeric substrates. Surf. Coat. Technol. 1996, 78, 1-9.

97. Roman, M.J.; Decker, E.A.; Goddard, J.M. Performance of nonmigratory iron chelating active packaging materials in viscous model food systems. J. Food Sci. 2015, 80, 1965-1973.

98. Fernández, A.; Cava, D.; Ocio, M.J.; Lagarón, J.M. Perspectives for biocatalysts in food packaging. Trends Food Sci. Technol. 2008, 19, 198-206.

99. Brody, A.L.; Budny, J.A. Enzymes as active packaging agents. In Active Food Packaging; Rooney, M.L., Ed.; Blackie Academic and Professional: New York, NY, USA, 1995; pp. 174-192.

100. Gemili, S.; Yemenicioğlu, A.; Altınkaya, S.A. Development of cellulose acetate based antimicrobial food packaging materials for controlled release of lysozyme. J. Food Eng. 2009, 90, 453-462.

101. Barbiroli, A.; Bonomi, F.; Capretti, G.; Iametti, S.; Manzoni, M.; Piergiovanni, L.; Rollini, M. Antimicrobial activity of lysozyme and lactoferrin incorporated in cellulose-based food packaging. Food Control 2012, 26, 387-392.

102. Mendes de Souza, P.; Fernandez, A.; Lopez-Carballo, G.; Gavara, R.; Hernandez-Munoz, P. Modified sodium caseinate films as releasing carriers of lysozyme. Food Hydrocoll. 2010, 24, 300-306.

103. Del Nobile, M.A.; Conte, A. Packaging for Food Preservation; Springer: New York, NY, USA, 2013; p. 270.

104. Andersson, M.; Andersson, T.; Adlercreutz, P.; Nielsen, T.; Hornsten, E. Toward an enzyme-based oxygen scavenging laminate. Influence of industrial lamination conditions on the performance of glucose oxidase. Biotechnol. Bioeng. 2002, 79, 37-42.

105. Talbert, J.N.; He, F.; Seto, K.; Nugen, S.R.; Goddard, J.M. Modification of glucose oxidase for the development of biocatalytic solvent inks. Enzyme Microb. Technol. 2014, 55, 21-25.

106. Talbert, J.N.; Goddard, J.M. Influence of nanoparticle diameter on conjugated enzyme activity. Food Bioprod. Process. 2013, 91, 693-699.

107. Talbert, J.N.; Goddard, J.M. Enzymes on material surfaces. Colloid Surf. B Biointerfaces 2012, 93 , 8-19.

108. Ge, L.; Zhao, Y.; Mo, T.; Li, J.; Li, P. Immobilization of glucose oxidase in electrospun nanofibrous membranes for food preservation. Food Control 2012, 26, 188-193.

109. Moskovitz, Y.; Srebnik, S. Mean-field model of immobilized enzymes embedded in a grafted polymer layer. Biophys. J. 2005, 89, 22-31.

110. Larsen, E.K.U.; Mikkelsen, M.B.L.; Larsen, N.B. Protein and cell patterning in closed polymer channels by photoimmobilizing proteins on photografted poly(ethylene glycol) diacrylate. Biomicrofluidics 2014, 8, doi:10.1063/1.4905093.

111. Larsen, E.K.U.; Mikkelsen, M.B.L.; Larsen, N.B. Facile photoimmobilization of proteins onto low-binding PEG-coated polymer surfaces. Biomacromolecules 2014, 15, 894-899. 
112. Realini, C.E.; Marcos, B. Active and intelligent packaging systems for a modern society. Meat Sci. 2014, 98, 404-419.

113. BCC Research. The Advanced Packaging Solutions Market Value for 2017 is Projected to be nearly \$44.3 Billion. 2015. Available online: http://www.bccresearch.com (accessed on 25 October 2015).

114. Day, B.P.F. Active packaging of foods. In Smart Packaging Technologies for Fast Moving Consumer Goods; Kerry, J.P., Butler, P., Eds.; Wiley \& Sons, Ltd.: West Sussex, UK, 2008; pp. $1-18$.

115. Lopez-Rubio, A.; Gavara, R.; Lagaron, J.A. Bioactive packaging: Turning foods into healthier foods through biomaterials. Trends Food Sci. Technol. 2006, 17, 567-575.

116. Koontz, J. Active Packaging Materials to Inhibit Lipid Oxidation: US Regulatory Framework. Int. News Fats Oils Relat. Mater. 2012, 23, 598-600.

117. Barnes, K.A.; Sinclair, C.R.; Watson, D.H. Chemical Migration and Food Contact Materials, 1st ed.; CRC: Boca Raton, FL, USA, 2007; p. 464.

118. Farris, S.; Introzzi, L.; Piergiovanni, L.; Cozzolino, C.A. Effects of different sealing conditions on the seal strength of polypropylene films coated with a bio-based thin layer. Ital. J. Food Sci. 2011, 23, $111-114$.

(C) 2015 by the authors; licensee MDPI, Basel, Switzerland. This article is an open access article distributed under the terms and conditions of the Creative Commons Attribution license (http://creativecommons.org/licenses/by/4.0/). 